\title{
PVPF tool: an automated web application for real-time photovoltaic power forecasting
}

\author{
Mohammad H. Alomari ${ }^{1}$, Jehad Adeeb ${ }^{2}$, and Ola Younis ${ }^{3}$ \\ ${ }^{1}$ Electrical Engineering Department, Applied Science Private University, Amman, Jordan \\ ${ }^{2}$ Renewable Energy Center, Applied Science Private University, Amman, Jordan \\ ${ }^{3}$ School of Electrical Engineering, Electronics and Computer Science, University of Liverpool, United Kingdom
}

\begin{tabular}{l}
\hline Article Info \\
\hline Article history: \\
Received Dec 29, 2017 \\
Revised Aug 1, 2018 \\
Accepted Aug 12, 2018 \\
\hline
\end{tabular}

\section{Keywords:}

Web Application

solar photovoltaic

PV forecasting

machine learning

weather data

global solar irradiance

\begin{abstract}
In this paper, we propose a fully automated machine learning based forecasting system, called Photovoltaic Power Forecasting (PVPF) tool, that applies optimised neural networks algorithms to real-time weather data to provide 24 hours ahead forecasts for the power production of solar photovoltaic systems installed within the same region. This system imports the real-time temperature and global solar irradiance records from the ASU weather station and associates these records with the available solar PV production measurements to provide the proper inputs for the pre-trained machine learning system along with the records' time with respect to the current year. The machine learning system was pre-trained and optimised based on the Bayesian Regularization (BR) algorithm, as described in our previous research, and used to predict the solar power PV production for the next 24 hours using weather data of the last five consecutive days. Hourly predictions are provided as a power/time curve and published in real-time at the website of the renewable energy center (REC) of Applied Science Private University (ASU). It is believed that the forecasts provided by the PVPF tool can be helpful for energy management and control systems and will be used widely for the future research activities at REC.
\end{abstract}

Copyright (c) 2019 Institute of Advanced Engineering and Science. All rights reserved.

\section{Corresponding Author:}

Mohammad H. Alomari,

Electrical Engineering Department,

Applied Science Private University,

166 Amman 11931 Jordan.

+962 5609999 Ext 1165

Email: m_alomari@asu.edu.jo

\section{INTRODUCTION}

Energy production by Photovoltaic (PV) systems is one of the significant clean energy sources that covers part of the increasing energy demand with the ongoing industrial growth [1]. Nowadays, many factors contributed to world energy problems, either a supply-demand or economic problems, among those factors are increasing world population, increasing living standards (directly related to energy consumption per capita), industrialization and modernization [2]. All these factors induced a global trend to utilize more renewable energy sources into countries' energy mix. Photovoltaic power plants have been widely utilized in the last decade, due to their simplicity, advantages of the technology and most importantly due to significantly decreased prices. One of the main challenges of integrating large PV installations into power systems is the stability of the power systems and how it is affected by intermittency of PV power plants [3].

Many researchers investigated various techniques used to forecast PV power, in order to facilitate power systems management and implementation of forecasting techniques into some application such as Elec- 
tric Vehicles (EV) charging stations, smart homes and smart grids. In [4], Traunmuller and Steinmaurer studied different techniques used to forecast solar irradiance and weather conditions and compared the achieved results. They also demonstrated the implementation of solar irradiance and weather condition forecasting into controlling the heating and cooling systems of an office building and its energy efficiency.

[5] presented a statistical method for PV power forecasting using artificial intelligence. The forecast horizon for the proposed method is 24 hour ahead, which is suitable for grid operators and PV plant operators trading in electricity markets. [6] presented a short-term solar irradiance forecasting model using artificial neural networks implementing statistical feature parameters. The proposed model is of great importance for grid tied PV plant operators to achieve optimum operation and power forecasting. In [7], the authors presented a novel short-term forecasting model based on a combined ensemble empirical mode decomposition and support vector machines, to achieve accurate hourly PV power forecasting for one day ahead. The proposed model is oriented toward integrating large-scale PV plants into power systems with economic dispatch. In [7] and [8], the authors presented a pair of articles as a benchmark of statistical regression methods used for short-term forecasting of PV plant's energy yield. The main objective of these two articles is to build a forecasting model of the hourly PV plant's energy yield for the next day, which can be utilized in various applications.

In [9], presented a new forecasting methodology using dynamic artificial neural networks for shortterm forecasting of PV power output. The presented methodology is claimed to be used to overcome dispatchability limitations of PV plants due to variable weather conditions. [10] presented a new approach, using artificial neural networks, for short-term forecasting of PV power for grid tied large-scale PV plants. The authors claimed that, due to the reliability of the method, grid operators would be well confident in evaluating the performance of the plant and in conducting dispatching plans.

[11] investigated various theoretical forecasting methods for solar irradiance and PV power. The aim of this work is to study the applications of solar forecasting in smart grid management, as the intermittency of solar energy is inherent, thus directly affecting the smart grid energy management and economic operations. Solar PV power forecasting can facilitate dealing with smart grid challenges such as voltage and frequency fluctuations and grid losses. In [12], the authors reviewed different solar forecasting methods along with the challenges and performance of each method. They concluded that solar forecasting is one of the most efficient and low cost techniques for efficiently integrating PV plants into power systems. [13] presented a new soft computing framework for accurate forecasting of solar radiation, to facilitate integration of renewable resources into grid, using a modified clustering technique, an innovative hourly time-series classification method, a new cluster selection algorithm and a multilayer perceptron neural network.

[14] proposed an alternative method to forecast solar power output using nonlinear regression model known as multivariate adaptive regression splines. The results illustrated that the model achieved reliable forecasting performance that can be utilized in various applications. [15] developed a short-term forecasting model based on extreme machine learning method for three grid connected PV systems. The proposed model is claimed to support integrating PV plants into power systems and that it is important for grid stability issues, economic dispatch, and regulations.

PV power forecasting is a must in some countries worldwide. For example, the national standard in China GB/T 19964-2012 on "Technical requirements for connecting photovoltaic power stations to power systems" requires 15-min to one-day ahead forecasts. These requirements are due to the variability of solar resources, which can cause sudden changes in generation capacity and affect power quality and grid stability. For this reason, [16] evaluated the economic feasibility of forecasting base on a case study in Henan province, China. They concluded that small deviations in forecasting frequency and forecasting corridor (accuracy) could lead to significant revenue losses since a penalty will be paid for jurisdictions in China. [17] studied the long-term performance and power prediction of PV technology in Qatar. One of their main findings is that the prediction of PV plant's energy yield is important in energy management, and machine-learning techniques and mathematical models can be implemented for this purpose. In [18] reviewed forecasting methods up to 2017, and they introduced an important information for researchers and engineers who are modeling and planning PV systems.

Our first forecasting model was proposed in [19] for the solar PV power production using neural networks and solar radiation records. Later in [20], the model has been improved by adding more weather inputs such as the temperature and time and two backpropagation algorithms were applied to neural networks: the Levenberg-Marquardt (LM) and the Bayesian Regularization (BR) algorithms. In this paper, we are presenting 
a novel web application that implements our previous research into a real-time prediction system providing power production forecasts for the next 24 hours.

This paper is organised as follows: Section 2 is describing the real-time data types and formats. The proposed real-time web tool is presented in section 3. Conclusions and future work plans are provided in section 4.

\section{REAL-TIME DATA}

Several PV plants are installed at the campus of Applied Science Private University (ASU) and the largest rooftop-mounted PV system is installed on top of the faculty of engineering building with a capacity of 264KWp [21]. PV power production data is available from the local web-boxes and from online sunnyportal system that can be accessed at www.sunnyportal.com providing hourly records as shown in Figure 1.

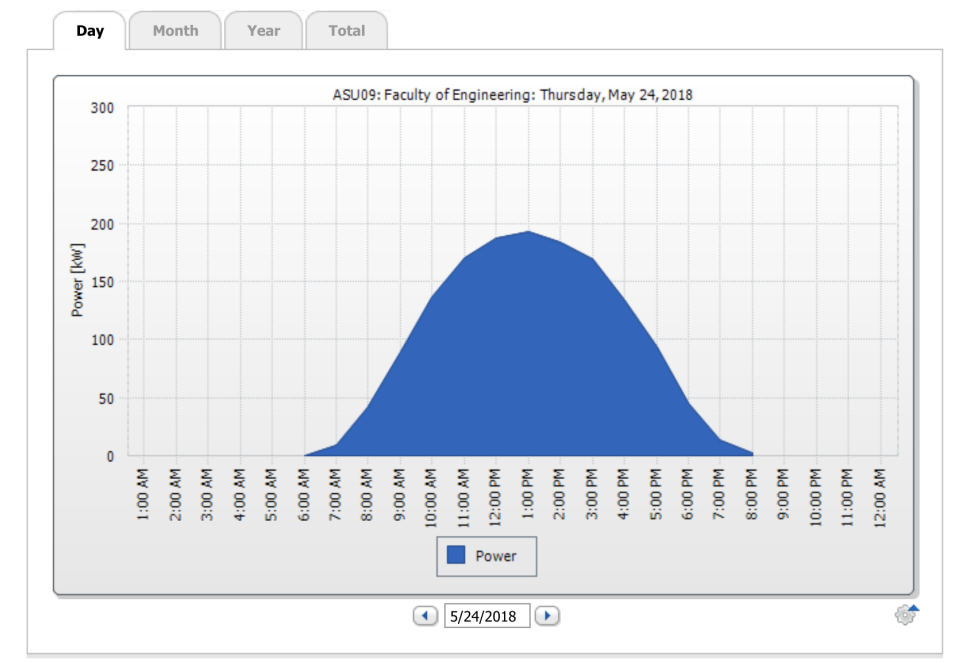

Figure 1. Sample data from www.sunnyportal.com for the plant PV ASU09 (Faculty of Engineering)

A wide range of measurement equipments for weather conditions are installed at ASU weather station as described in [20]. More information about these equipments is available at the REC website [22] (see Figure 2). The weather station data is collected from the Thies CLIMA DL16 Data logger using the Measurement and Visualization software (MEVIS) at REC workstation. A sample from this data is listed in Table 1.
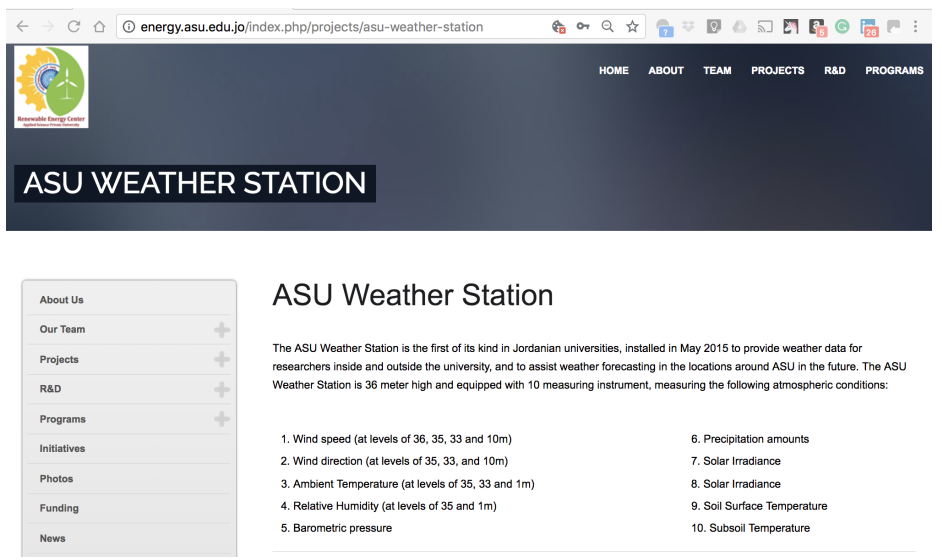

ASU Weather Station

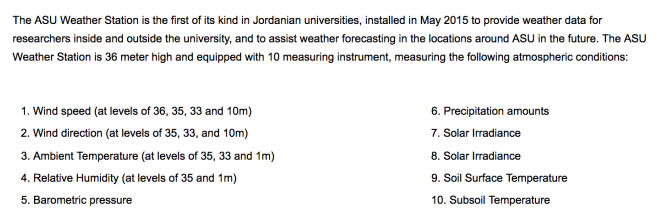

Figure 2. A screenshot from the weather station page at the REC website 
Table 1. Part of the Available Weather Station Data for 21 May 2015

\begin{tabular}{|c|c|c|c|c|c|c|c|c|c|c|}
\hline $\begin{array}{l}\text { Station: } \\
\text { Channel: }\end{array}$ & $\begin{array}{c}\text { DL16 } \\
\text { WS } \\
10 \mathrm{~m} \\
\mathrm{~m} / \mathrm{s}\end{array}$ & $\begin{array}{c}\text { DL16 } \\
\text { Air } \\
\text { pressure } \\
\text { hPa }\end{array}$ & $\begin{array}{c}\text { DL16 } \\
\text { Hum } \\
1 \mathrm{~m} \\
\%\end{array}$ & $\begin{array}{c}\text { DL16 } \\
\text { Hum } \\
35 \mathrm{~m} \\
\%\end{array}$ & $\begin{array}{c}\text { DL16 } \\
\text { Temp } \\
1 \mathrm{~m} \\
{ }^{\circ} \mathrm{C}\end{array}$ & $\begin{array}{l}\text { DL16 } \\
\text { Temp } \\
35 \mathrm{~m} \\
{ }^{\circ} \mathrm{C}\end{array}$ & $\begin{array}{c}\text { DL16 } \\
\text { Rad1 } \\
\text { Global } \\
\text { W/m }\end{array}$ & $\begin{array}{c}\text { DL16 } \\
\text { Rad2 } \\
\text { Diffuse } \\
\text { W/m }\end{array}$ & $\begin{array}{l}\text { DL16 } \\
\text { Precip }\end{array}$ & $\begin{array}{c}\text { DL16 } \\
\text { Rad3 } \\
\text { Direct } \\
W / m\end{array}$ \\
\hline 5/21/2015 12:00AM & 1.8 & 907.9 & 18.2 & 17 & 22 & 23.1 & -3 & -3 & 0 & 0 \\
\hline 5/21/2015 1:00AM & 1.7 & 907.6 & 17.8 & 16.6 & 22 & 23.1 & -3 & -3 & 0 & 0 \\
\hline 5/21/2015 2:00AM & 1.9 & 907.2 & 17.7 & 16.8 & 21.9 & 22.8 & -3 & -3 & 0 & 0 \\
\hline 5/21/2015 3:00AM & 1.8 & 907 & 18.3 & 16.8 & 21.5 & 22.7 & -3 & -3 & 0 & 0 \\
\hline 5/21/2015 4:00AM & 3.8 & 907.1 & 22.5 & 22.2 & 20.6 & 21.1 & -3 & -2 & 0 & -1 \\
\hline 5/21/2015 5:00AM & 3.9 & 907.3 & 27.8 & 27.7 & 19.3 & 19.6 & -3 & -2 & 0 & -1 \\
\hline 5/21/2015 6:00AM & 4.3 & 907.8 & 35.2 & 35.3 & 18.5 & 18.7 & 6 & 4 & 0 & 1 \\
\hline 5/21/2015 7:00AM & 4.5 & 908 & 37.4 & 37.5 & 19.1 & 19 & 129 & 50 & 0 & 78 \\
\hline 5/21/2015 8:00AM & 4.6 & 908.1 & 37.5 & 38.6 & 20.3 & 19.6 & 346 & 81 & 0 & 266 \\
\hline 5/21/2015 9:00AM & 5 & 908.6 & 36.5 & 38.7 & 21.3 & 20 & 571 & 101 & 0 & 470 \\
\hline 5/21/2015 10:00AM & 4.8 & 908.6 & 31.3 & 34.1 & 23.1 & 21.3 & 758 & 115 & 0 & 644 \\
\hline 5/21/2015 11:00AM & 5.3 & 908.5 & 26.2 & 29.2 & 24.3 & 22 & 915 & 121 & 0 & 794 \\
\hline 5/21/2015 12:00PM & 4.8 & 908.4 & 25.7 & 29.2 & 25.1 & 22.6 & 1000 & 133 & 0 & 867 \\
\hline 5/21/2015 1:00PM & 4.6 & 908.3 & 32.3 & 37.4 & 25.4 & 22.5 & 1020 & 144 & 0 & 876 \\
\hline 5/21/2015 2:00PM & 5.2 & 908 & 39.2 & 45.6 & 25.3 & 22.5 & 927 & 163 & 1.5 & 764 \\
\hline 5/21/2015 3:00PM & 5.5 & 907.8 & 41.7 & 48.6 & 25.1 & 22.3 & 886 & 157 & 0 & 728 \\
\hline 5/21/2015 4:00PM & 5.5 & 907.5 & 44.9 & 52.3 & 24.8 & 22 & 737 & 147 & 0 & 589 \\
\hline 5/21/2015 5:00PM & 5.4 & 907.2 & 46.7 & 54 & 24 & 21.5 & 540 & 129 & 0 & 411 \\
\hline 5/21/2015 6:00PM & 5.9 & 907 & 50.7 & 57.1 & 22.6 & 20.6 & 327 & 98 & 0 & 229 \\
\hline 5/21/2015 7:00PM & 5.6 & 907 & 54.5 & 58.9 & 20.7 & 19.4 & 120 & 56 & 0 & 64 \\
\hline 5/21/2015 8:00PM & 5.6 & 907.1 & 66.2 & 69.2 & 17.9 & 17.2 & 6 & 5 & 0 & 0 \\
\hline 5/21/2015 9:00PM & 5.9 & 907.3 & 75.6 & 78.4 & 16.1 & 15.6 & -2 & -2 & 0 & 0 \\
\hline 5/21/2015 10:00PM & 5 & 907.8 & 82.2 & 84.8 & 15 & 14.5 & -3 & -2 & 0 & -1 \\
\hline 5/21/2015 11:00PM & 5.8 & 907.7 & 84.7 & 86.9 & 14.3 & 13.8 & -2 & -2 & 0 & -1 \\
\hline
\end{tabular}

\section{THE PVPF TOOL}

As described before, the PVPF tool is the application that implements our previous research into a real-time online forecasting system. A set of software interfaces have been developed to link and import data from the Thies CLIMA DL16 Data logger and the SMA Sunny Web-box of the PV ASU09 (Faculty of Engineering) system, as depicted in Figure 3.

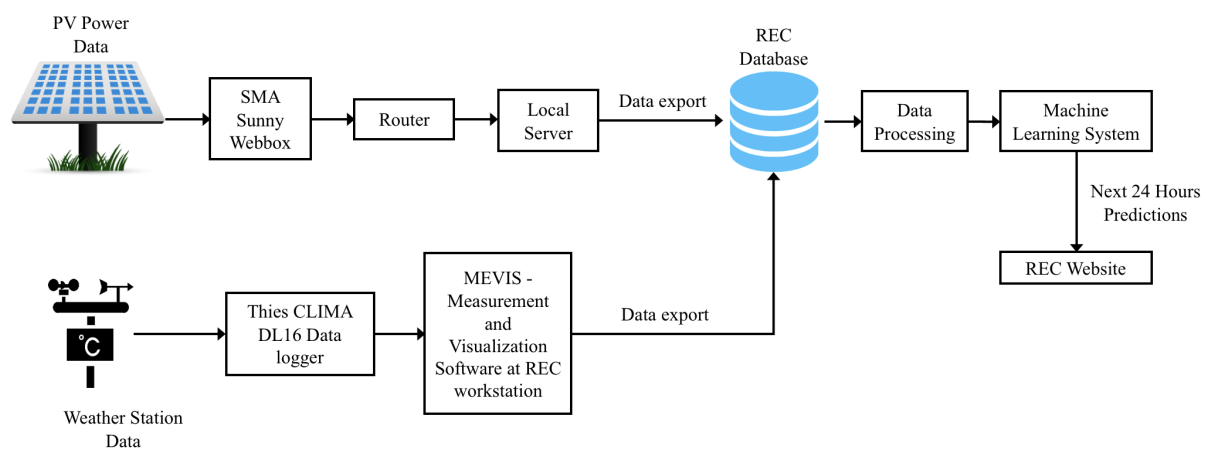

Figure 3. The proposed PVPF tool 
Data is stored at the REC database ready for the the data processing stage which includes: filtering extra data records, synchronising timing stamps, normalisation, and inserting correction values for missing records based on history data. Then, the processed data vectors are sorted in a proper way to be accepted by the machine learning system. This set of vectors represents the weather station data for the previous five days (24 hours per day) as depicted in Figure 4.

Then, the predictions provided by the machine learning system are provided as a power/time curve which is published in real time online at the REC website. A sample result for the predicted power production on 12 June 2015 is shown in Figure 5 based on weather data of the previous five days. The system automatically provides the measured solar PV production on the same curve, once available from the SMA sunny web-box.
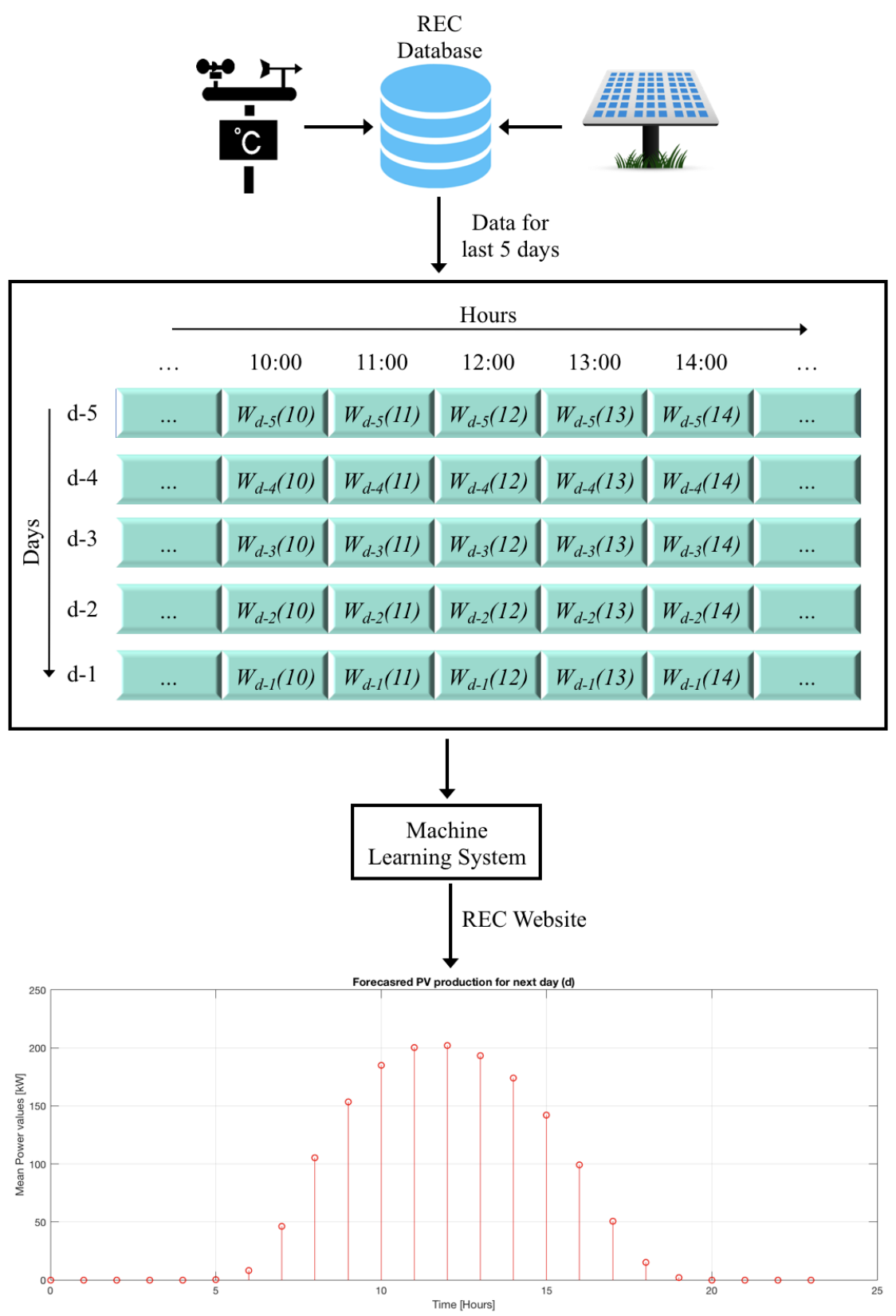

Figure 4. Next-day PV forecasting based on the weather data of the previous five consecutive days 


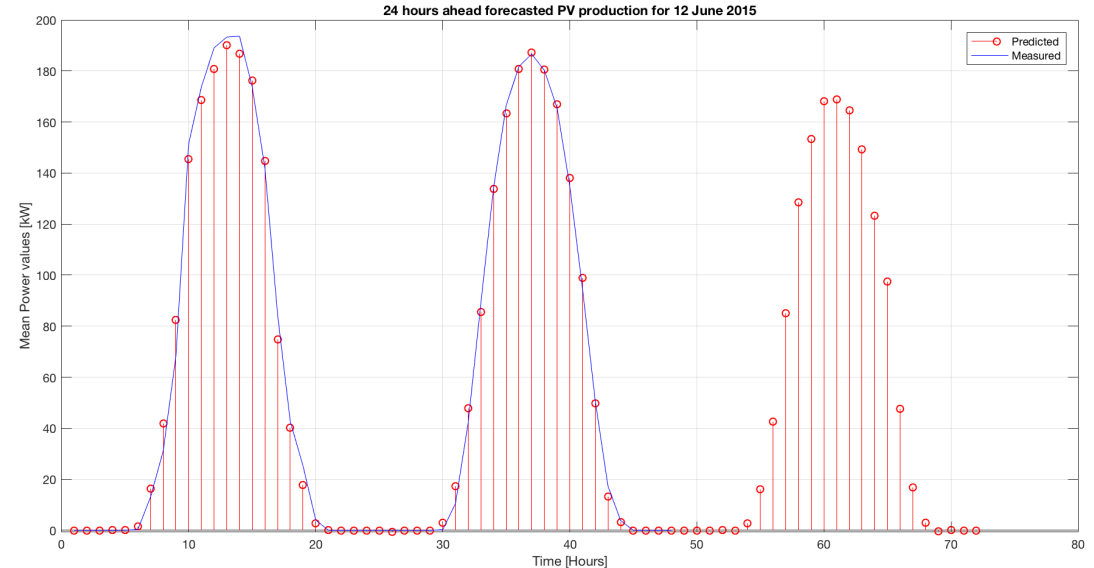

Figure 5. Measured power production for 10-11 June 2015 and automated forecasting results for 10-12 June 2015

\section{CONCLUSIONS}

In this research, we have presented an automated PV power forecasting system that applies the Bayesian Regularization algorithm to neural networks to predict the next-day hourly power production based on weather data for the last five days. The real-time PVPF is running on the website of the renewable energy center at http://energy.asu.edu.jo since Dec 2017. In a fully automated process, the system imports the weather station data from the Thies CLIMA DL16 Data logger and the solar PV power production data from the SMA Sunny Web-box. After running the sequence of data processing steps described in this research work, the set of input vectors are passed into the machine learning system which provides the required forecasts in a publishable format.

It is believed that this work can help researchers in the field of energy resource management and can be used as an assistive tool by the staff of the renewable energy center who are responsible for monitoring the current PV plants, installed at Applied Science Private University, and planning for the energy needs on campus.

In our future plans, the tool will be validated on several buildings (plants) providing the forecasts for all installed PV systems. In addition, the measured PV power production values can be used as a feedback input to the machine learning system to form an adaptable hybrid system that can improve the prediction accuracy with time. Moreover, the tool will be developed to generate a set of weather and energy data logs that can be published publicly on our website.

\section{ACKNOWLEDGEMENT}

The authors would like to acknowledge the financial support received from Applied Science Private University that helped in accomplishing the work of this article.

\section{REFERENCES}

[1] I. E. Agency, "Technology roadmap: Solar photovoltaic energy 2014 edition," Paris, France, 2014, last accessed: 2017-10-2. [Online]. Available: https://goo.gl/6opzZ8

[2] U. K. Das, K. S. Tey, M. Seyedmahmoudian, S. Mekhilef, M. Y. I. Idris, W. V. Deventer, B. Horan, and A. Stojcevski, "Forecasting of photovoltaic power generation and model optimization: A review," Renewable and Sustainable Energy Reviews, vol. 81, pp. 912 - 928, 2018. [Online]. Available: http://www.sciencedirect.com/science/article/pii/S1364032117311620

[3] R. Shah, N. Mithulananthan, R. Bansal, and V. Ramachandaramurthy, "A review of key power system stability challenges for large-scale pv integration," Renewable and 
Sustainable Energy Reviews, vol. 41, pp. 1423 - 1436, 2015. [Online]. Available: http://www.sciencedirect.com/science/article/pii/S1364032114008004

[4] Solar Irradiance Forecasting, Benchmarking of Different Techniques and Applications of Energy Meteorology. Graz, Austria: ISES, 28 September - 1 October 2010.

[5] C. Chen, S. Duan, T. Cai, and B. Liu, "Online 24-h solar power forecasting based on weather type classification using artificial neural network," Solar Energy, vol. 85, no. 11, pp. 2856 - 2870, 2011. [Online]. Available: http://www.sciencedirect.com/science/article/pii/S0038092X11003008

[6] F. Wang, Z. Mi, S. Su, and H. Zhao, "Short-term solar irradiance forecasting model based on artificial neural network using statistical feature parameters," Energies, vol. 5, no. 5, pp. 1355-1370, 2012. [Online]. Available: http://www.mdpi.com/1996-1073/5/5/1355

[7] M. Mao, W. Gong, and L. Chang, "Short-term photovoltaic output forecasting model for economic dispatch of power system incorporating large-scale photovoltaic plant," in 2013 IEEE Energy Conversion Congress and Exposition, Sept 2013, pp. 4540-4545.

[8] M. Zamo, O. Mestre, P. Arbogast, and O. Pannekoucke, "A benchmark of statistical regression methods for short-term forecasting of photovoltaic electricity production. part ii: Probabilistic forecast of daily production," Solar Energy, vol. 105, pp. 804 - 816, 2014. [Online]. Available: http://www.sciencedirect.com/science/article/pii/S0038092X14001601

[9] F. Almonacid, P. Pérez-Higueras, E. F. Fernández, and L. Hontoria, "A methodology based on dynamic artificial neural network for short-term forecasting of the power output of a pv generator," Energy Conversion and Management, vol. 85, pp. 389 - 398, 2014. [Online]. Available: http://www.sciencedirect.com/science/article/pii/S0196890414005093

[10] A. Mellit, A. M. Pavan, and V. Lughi, "Short-term forecasting of power production in a large-scale photovoltaic plant," Solar Energy, vol. 105, pp. 401 - 413, 2014. [Online]. Available: http://www.sciencedirect.com/science/article/pii/S0038092X14001522

[11] C. Wan, J. Zhao, Y. Song, Z. Xu, J. Lin, and Z. Hu, "Photovoltaic and solar power forecasting for smart grid energy management," CSEE journal of Power and Energy Systems, vol. 1, no. 4, pp. 38-46, Dec 2015.

[12] A. Tuohy, J. Zack, S. E. Haupt, J. Sharp, M. Ahlstrom, S. Dise, E. Grimit, C. Mohrlen, M. Lange, M. G. Casado, J. Black, M. Marquis, and C. Collier, "Solar forecasting: Methods, challenges, and performance," IEEE Power and Energy Magazine, vol. 13, no. 6, pp. 50-59, Nov 2015.

[13] M. Ghofrani, M. Ghayekhloo, and R. Azimi, "A novel soft computing framework for solar radiation forecasting," Applied Soft Computing, vol. 48, pp. 207 - 216, 2016. [Online]. Available: http://www.sciencedirect.com/science/article/pii/S1568494616303489

[14] Y. Li, Y. He, Y. Su, and L. Shu, "Forecasting the daily power output of a grid-connected photovoltaic system based on multivariate adaptive regression splines," Applied Energy, vol. 180, pp. 392 - 401, 2016. [Online]. Available: http://www.sciencedirect.com/science/article/pii/S0306261916309941

[15] M. Hossain, S. Mekhilef, M. Danesh, L. Olatomiwa, and S. Shamshirband, "Application of extreme learning machine for short term output power forecasting of three grid-connected pv systems," journal of Cleaner Production, vol. 167, pp. 395 - 405, 2017. [Online]. Available: http://www.sciencedirect.com/science/article/pii/S0959652617317973

[16] T. Reindl, W. Walsh, Z. Yanqin, and M. Bieri, "Energy meteorology for accurate forecasting of pv power output on different time horizons," Energy Procedia, vol. 130, pp. 130 - 138, 2017, proceedings of the SNEC 11th International Photovoltaic Power Generation Conference and Exhibition, SNEC 2017 Scientific Conference. [Online]. Available: http://www.sciencedirect.com/science/article/pii/S187661021734506X

[17] F. Touati, N. A. Chowdhury, K. Benhmed, A. J. S. P. Gonzales, M. A. Al-Hitmi, M. Benammar, A. Gastli, and L. Ben-Brahim, "Long-term performance analysis and power prediction of pv technology in the state of qatar," Renewable Energy, vol. 113, pp. 952 - 965, 2017. [Online]. Available: http://www.sciencedirect.com/science/article/pii/S0960148117305827

[18] S. Sobri, S. Koohi-Kamali, and N. A. Rahim, "Solar photovoltaic generation forecasting methods: A review," Energy Conversion and Management, vol. 156, pp. 459 - 497, 2018. [Online]. Available: http://www.sciencedirect.com/science/article/pii/S0196890417310622

[19] M. H. Alomari, J. Adeeb, and O. Younis, "Solar photovoltaic power forecasting in jordan using artificial 
neural networks," International journal of Electrical and Computer Engineering, vol. 8, no. 1, pp. 497504, February 2018.

[20] M. H. Alomari, O. Younis, and S. Hayajneh, "Solar photovoltaic power forecasting in jordan using artificial neural networks," International journal of Advanced Computer Science and Applications, vol. 9, no. 1, p. (Online First: Jan 2018), February 2018.

[21] ASU, "Pv system asu09: Faculty of engineering," 2017, last accessed: 2017-10-14. [Online]. Available: https://goo.gl/cxGYVb

[22] U. ASU, "Renewable energy center," 2018, last accessed: 2018-1-15. [Online]. Available: http://energy.asu.edu.jo/

\section{BIOGRAPHY OF AUTHORS}

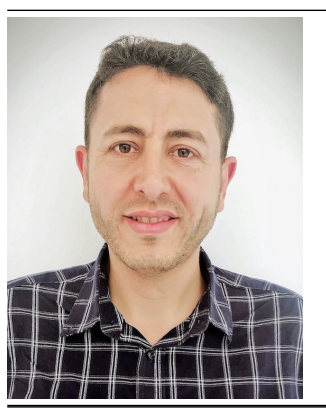

Mohammad Alomari is currently an Associate Professor of Electrical Engineering (Solar Systems) at Applied Science Private University, Jordan. He received his B.Sc. and M.S. degrees in Electrical Engineering (Communications and Electronics) from Jordan University of Science and Technology, Irbid, Jordan, in 2005 and 2006, respectively and the PhD degree from the University of Bradford in 2009. His research interests include smart and green buildings, solar PV applications, space weather and solar energy, computer vision, brain computer interface and digital image processing.

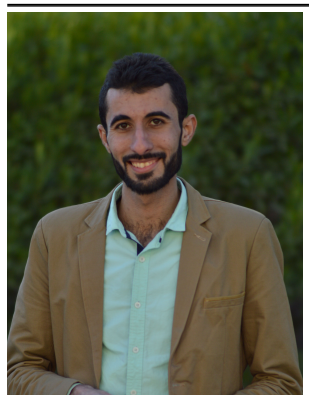

Jehad Adeeb received his B.Sc. degree in Mechanical Engineering from Al-Balqa Applied University - FET, Amman, Jordan in 2015. He is currently enrolled in M.S. program in Renewable Energy Engineering at The University of Jordan, Amman, Jordan. He is working as Renewable Energy Engineer at REC - ASU. His research interests include renewable energy and energy efficiency, green building, energy management systems and PV panels technologies.

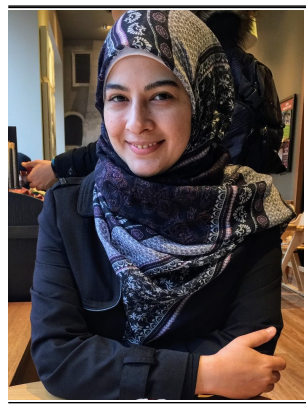

Ola Younis is currently a full-time PhD student at the School of Electrical Engineering, Electronics and Computer Science at the University of Liverpool, United Kingdom. She received her B.Sc. degree in Computer Science from Jordan University of Science and Technology, Irbid, Jordan, in 2010 and her M.S. degree in 2012 from Philadelphia University, Jordan. Her research interests include digital signal, image, and video processing, computer vision, vision impairment assistive technology, and Bio-inspired Software Engineering. 